\title{
Persistent Repression of a Functional Allele Can Be Responsible for Galactosyltransferase Deficiency in Tn Syndrome
}

\author{
Martin Thurnher, * Sandro Rusconi, ${ }^{*}$ and Eric G. Berger * \\ ${ }^{*}$ Institutes of Physiology and ${ }^{\ddagger}$ Molecular Biology II, University of Zurich, Zurich, Switzerland
}

\begin{abstract}
A human hematopoietic disorder designated as Tn syndrome or permanent mixed-field polyagglutinability has been ascribed to a stem cell mutation leading to a specific deficiency of UDP-Gal:GalNAc $\alpha$ 1-O-Ser/Thr $\beta$ 1-3 galactosyltransferase $(\beta 3 \mathrm{Gal}-\mathrm{T})$ activity in affected cells. To test for the possibility that an allele of the $\beta 3 \mathrm{Gal}-\mathrm{T}$ gene might be repressed instead of mutated, we have investigated whether 5-azacytidine or sodium $n$-butyrate, both inducers of gene expression, would reactivate expression of $\beta 3 \mathrm{Gal}-\mathrm{T}$ in cloned enzyme-deficient $\mathrm{T}$ cells derived from a patient affected by the $T n$ syndrome. Flow cytometry revealed that a single treatment induced de novo expression of the Thomsen-Friedenreich antigen (GalB1-3GalNAc-R), the product of $\beta 3 \mathrm{Gal}-\mathrm{T}$ activity. In addition, a sialylated epitope on CD43 (leukosialin), which is present on normal but not on $\beta 3 \mathrm{Gal}-\mathrm{T}$-deficient $\mathrm{T}$ cells, was also reexpressed. Although no $\beta 3 \mathrm{Gal}-\mathrm{T}$ activity was detectable in untreated $\mathrm{T}$ syndrome $\mathrm{T}$ cells, after exposure to 5-azaC, $\beta 3 \mathrm{Gal}-\mathrm{T}$ activity reached nearly normal values. Both agents failed to reactivate $\beta 3 \mathrm{Gal}-\mathrm{T}$ in Jurkat $\mathrm{T}$ leukemic cells, which also lack $\beta 3 \mathrm{Gal}-\mathrm{T}$ activity. These data demonstrate that $T n$ syndrome $T$ cells contain an intact $\beta 3 \mathrm{Gal}-\mathrm{T}$ gene copy and that the enzyme deficiency in this patient is due to a persistent and complete but reversible repression of a functional allele. In contrast, the cause of $\beta 3 \mathrm{Gal}-\mathrm{T}$ deficiency appears to be different in Jurkat T cells. ( $J$. Clin. Invest. 1993. 91:2103-2110.) Key words: $T$ cells $\bullet$ 5-azacytidine - sodium butyrate • Tn antigen - CD43
\end{abstract}

\section{Introduction}

Tn syndrome or permanent mixed-field polyagglutinability (PMFP) ${ }^{1}$ is a human disorder characterized by the exposure of truncated O-glycans, in particular the Tn antigen (GalNAc $\alpha$ 1$O$-Ser/Thr) (1) due to a selective deficiency of UDP-Gal:GalNAc $\alpha 1-O-S e r / T h r \beta 1-3$ galactosyltransferase ( $\beta 3 \mathrm{Gal}-\mathrm{T})$ activ-

Address correspondence to Dr. Eric G. Berger, Institute of Physiology, University of Zurich, Winterthurerstrasse 190, CH-8057 Zurich, Switzerland.

Received for publication 16 September 1992 and in revised form 30 November 1992.

1. Abbreviations used in this paper: APC, antigen-presenting cells; asialo-OSM, sialic acid-free ovine submaxillary mucin; $\beta 3 \mathrm{Gal}-\mathrm{T}$, UDP-Gal:GalNAC-R $\beta 1 \rightarrow 3$ galactosyltransferase (EC 2.4.1.122); 5azaC, 5-azacytidine; HS, human serum; MFI, mean channel of fluorescence intensity; $\mathrm{NaB}$, sodium $n$-butyrate; PMFP, permanent mixedfield polyagglutinability.

\footnotetext{
J. Clin. Invest.

(c) The American Society for Clinical Investigation, Inc.

$0021-9738 / 93 / 05 / 2103 / 08 \$ 2.00$

Volume 91, May 1993, 2103-2110
}

ity $(2,3)$ in a variable proportion of hematopoietic cells (4). These patients, who are also said to have blood group Tn (5), occasionally develop hemolytic anemia, thrombopenia, and leukopenia most likely mediated by anti-Tn natural antibodies present in normal serum (6). Tn polyagglutinability has been observed in the context of hemoproliferative disorders (7) and Tn antigen expression may also accompany malignant transformation (8). The enzyme deficiency was thought to arise from a somatic stem cell mutation resulting in the clonal penetration of $\mathrm{T} n$ antigen-expressing cells into the various hematopoietic lineages (9). Thus, Tn antigen-expressing cells circulating in peripheral blood of PMFP patients have been considered glycosylation variants carrying a somatic mutation that has irreversibly destroyed $\beta 3 \mathrm{Gal}-\mathrm{T}$ activity.

In principle, absence of a functional gene product may be due to either mutation or repression. In the context of blood group biosynthesis, an example of a mutated gene is observed in the histoblood group ABO system (10). A single-base deletion in the $\mathrm{O}$ allele causing a frame-shift leads to expression of a nonfunctional protein, whereas in case of A or B genotypes, functionally active glycosyltransferases are produced. On the other hand, stable gene repression with mutation-like characteristics is well known to occur in transformed permanent cell lines (11). This appears to be, however, a phenomenon induced in vitro by cell culture conditions selecting for rapid growth, which lead to the silencing of nonessential genes. The loss of specific functions was originally ascribed to structural gene mutations and the new isolates were designated as mutants. However, many of these "mutants" could be reverted by treatment with 5-azacytidine $(5$-azaC), a potent inhibitor of DNA methylation $(12,13)$. DNA methylation is also thought to play a role in gene regulation during blood cell differentiation. The IL-3-dependent multipotential stem cell clone LyD9 could be induced to differentiate into neutrophils and macrophages without direct contact with stromal cells by pretreatment with 5-azaC (14). Furthermore, 5-azaC reactivates expression of CD4 on CD8+ peripheral blood T cells (15), suggesting that DNA hypermethylation also correlates with persistent repression of gene activity during maturation of human $\mathrm{T}$ cells. This observation is substantiated by the fact that acquisition of glucocorticoid resistance of human $T$ cells is accompanied by de novo DNA methylation and sensitivity may be recovered after treatment with 5 -azaC (16). In addition, 5 -azaC has been used to induce constitutive IL-2 production in EL-4 thymoma cells (17).

Other agents that are known to induce different expression of phenotypic and functional properties include sodium $n$-butyrate ( $\mathrm{NaB}$ ) and DMSO, well known for their differentiationinducing effect on human promyelocytic HL-60 cells and murine erythroleukemia cells (18-20). While gene expression could also be induced in $\mathrm{T}$ lymphoid cells by $\mathrm{NaB}$, as demonstrated by the finding that latent HIV-1 could be reactivated in chronically infected cells (21), DMSO appeared to be less ef- 
fective as an inducer of gene expression in B and T lymphoid cells (22). Thus, 5 -azaC and $\mathrm{NaB}$ should be useful agents to activate possibly intact but silent genes in human $\mathrm{T}$ cells.

In PMFP patients, $\mathrm{Tn}+$ cells deficient in $\beta 3 \mathrm{Gal}-\mathrm{T}$ activity and $\mathrm{TF}+$ cells containing enzyme activity levels comparable with cells from control subjects coexist in peripheral blood. This "mosaic status" in PMFP peripheral blood strongly suggested that $\mathrm{Tn}$ expression arises from a somatic mutation in a pluripotent stem cell followed by clonal expansion into the various lineages (5). To test the alternative possibility that PMFP represents an example of a disorder caused by repression of an otherwise intact $\beta 3 \mathrm{Gal}-\mathrm{T}$ gene, we have investigated $T$ cells deficient in $\beta 3 \mathrm{Gal}-\mathrm{T}$ activity. For this purpose, we took advantage from $\mathrm{Tn}+\mathrm{T}$ cell clones recently established in our laboratory from the PBL of a well-characterized patient (R.R.) (4). These Tn+T cells represented nontransformed cells reflecting an in vivo situation and thus provided a system to investigate whether repression of a functional allele of the $\beta 3 \mathrm{Gal}-\mathrm{T}$ gene may be responsible for the enzyme deficiency. Here we report that PMFP T cells reexpress $\beta 3 \mathrm{Gal}-\mathrm{T}$ activity after exposure to 5 -azaC or $\mathrm{NaB}$, resulting in surface expression of the TF antigen (Gal $\beta 1$-3GalNAc-R). Moreover, 5-azaC induces reconstitution of a sialylated epitope on CD43 (leukosialin), which is present on normal but not on PMFP T cells. Our data indicate that galactosyltransferase deficiency in PMFP arises from the silencing of an intact $\beta 3 \mathrm{Gal}-\mathrm{T}$ allele. In contrast, $5-\mathrm{azaC}$ and $\mathrm{NaB}$ did not reactivate $\beta 3 \mathrm{Gal}-\mathrm{T}$ in transformed $T$ cells (Jurkat).

\section{Methods}

Antibodies. TKH6 (IgM anti-Tn) and HH8 (IgM anti-TF) mAb were described previously $(4,23)$. DF-T1, the sialic acid (NeuAc)-dependent mAb anti-CD43 ( IgG1) (24) was purchased from Dakopatts (Copenhagen, Denmark). The epitope recognized by DF-T1 was designated $\mathrm{CD} 43_{\mathrm{NeuAc}}$ in this work. Binding of $\mathrm{mAb}$ was revealed by fluoresceinated goat anti-mouse Ig (Southern Biotechnology Associates, Birmingham, AL).

Culture media. The culture medium IMDM (Gibco Laboratories, Grand Island, NY) was supplemented with L-glutamine $(300 \mu \mathrm{g} / \mathrm{ml}))$, $1 \%$ ( vol/vol) of a $100 \times$ mixture of nonessential aminoacids, $100 \mathrm{U} / \mathrm{ml}$ penicillin, $100 \mu \mathrm{g} / \mathrm{ml}$ streptomycin, and $10 \%$ ( $\mathrm{vol} / \mathrm{vol}$ ) heat-inactivated fetal calf serum (IMDM-FCS) or $5 \%$ ( $\mathrm{vol} / \mathrm{vol}$ ) pooled human A serum (IMDM-HS). To support growth of T cell clones, IMDM-HS was supplemented with $100 \mathrm{U} / \mathrm{ml}$ recombinant human IL-2 (generously supplied by Dr. F. Sinigaglia, Hoffmann-La Roche, Basel, Switzerland).

$T$ cell lines and culture. The generation and characterization of the CD4+ PMFP T cell clone used in this study has been described recently (4). Briefly, the Tn+ subpopulation of the PBL from patient R.R. was enriched by a negative sorting on a fluorescence activated cell sorter. $T$ cells contained in this fraction were activated with $1 \mu \mathrm{g} / \mathrm{ml} \mathrm{PHA}$ (Wellcome Diagnostic, Greenville, NC) in IMDM-HS-IL-2. For cloning, T blasts were seeded in Terasaki plates at 0.2 cells per well in the presence of PHA and $5 \times 10^{5} / \mathrm{ml}$ allogeneic irradiated (3,500 rad), freshly taken, PBMC in IMDM-HS-IL-2. After 8-10 d, wells were scored microscopically and growing $T$ cell clones were expanded in 96- and 24well plates, respectively. For restimulation, $2-4 \times 10^{5} \mathrm{~T}$ cells and $10^{6}$ antigen-presenting cells (APC) were incubated in $2 \mathrm{ml}$ of IMDM-HSIL-2 containing PHA. Control cultures were set up to exclude growth of APC. No growth was observed in these cultures. T cells were expanded and maintained in culture by periodic restimulation (1-2 wk). The Jurkat cell line was kindly provided by Dr. A. de la Hera (Basel Insti- tute for Immunology, Basel, Switzerland). A clone was established by limiting dilution ( 0.3 cells per well). This Jurkat cell clone was routinely cultured in IMDM-FCS at a density of 0.2 to $1 \times 10^{6}$ cells $/ \mathrm{ml}$.

Preparation of $A P C$. Heparinized peripheral blood and HS were obtained from normal blood donors at the Swiss Red Cross in Zurich. PBMC were separated by density gradient centrifugation on FicollPaque (Pharmacia Inc., Piscataway, NJ) according to the method of Böyum (25). Cells were washed twice, irradiated at 3,500 rads (Cobalt source), and frozen in liquid nitrogen. Just before use, cells were thawed quickly, washed twice, and suspended in IMDM-HS-IL-2.

Drug treatment of $T$ cells. T cell clones were restimulated in 24-well plates ( $2 \mathrm{ml}$ per well). During peak proliferation, which was usually on day 3, half of the supernatant was removed. 5-azaC (Sigma Chemical Co., St. Louis, MO) was prepared as a $4 \mathrm{mM}$ stock solution in IMDM and immediately diluted in one step into IMDM-HS-IL-2 to yield a $2 \times$ solution of which $1 \mathrm{ml}$ was added to an equal volume of restimulated T cells. After treatment the cells were allowed to grow for 2 wk. Since 5 -azaC is rapidly hydrolyzed in aqueous solution (26), no attempt was made to remove it from the cells. Untreated PMFP T cells (control cells) were always aliquotted from the same restimulation. NaB (Sigma Chemical Co.) was prepared as a $0.5 \mathrm{M}$ stock solution in water and stored at $4^{\circ} \mathrm{C}$. NaB stock was diluted in one step into IMDM-HS-IL-2 and added to the cells during log-phase growth. In contrast to the treatment with 5-azaC, which was followed by a growth period, cells were exposed to $\mathrm{NaB}$ for the times indicated and then immediately analyzed. In addition, T cells were treated with $1.5 \%$ ( vol/vol) DMSO (Merck Inc., Rahway, NJ). The treated cells were analyzed after 24, 48, and $72 \mathrm{~h}$. Jurkat $\mathrm{T}$ cells were treated three times at weekly intervals with 5-azaC at $2 \mu \mathrm{M}$ followed by a 6-d growth period and analyzed for de novo expression of the TF antigen. $\mathrm{NaB}$ treatment of Jurkat cells was for $24 \mathrm{~h}$ at $5 \mathrm{mM}$. Viability under these conditions was $\sim 20 \%$ as tested by trypan blue exclusion.

Neuraminidase treatment. For detection of TF antigen, $10^{7} \mathrm{~T}$ cells were desialylated with $20 \mathrm{mU}$ Vibrio cholerae neuraminidase (Boehringer Mannheim GmBH, Mannheim, Germany) in $1 \mathrm{ml}$ PBS $/ 0.1 \%$ (wt/vol) BSA for $45 \mathrm{~min}$ at $37^{\circ} \mathrm{C}$. The cells were washed twice with PBS containing $1 \%$ ( vol/vol) FCS.

Flow cytometry and cell sorting. T cells were stained at $10^{6}$ cells/ $100-\mu \mathrm{l}$ sample for $30 \mathrm{~min}$ at $4^{\circ} \mathrm{C}$. Cells were first stained with culture supernatant from the appropriate B cell hybridoma, followed by fluoresceinated goat anti-mouse Ig (in PBS/20\% NHS). After each incubation cells were washed twice with PBS/1\% FCS. After the final wash, cells were fixed in $2 \%$ ( vol/ vol) formaldehyde in PBS containing $0.1 \%$ BSA (the fixative was filtered before use) and kept at $4^{\circ} \mathrm{C}$ in the dark until analysis. Cells were analyzed for immunofluorescence on a flow cytometer (EPICS Profile I). When T cells were analyzed at least $2 \mathrm{wk}$ after restimulation, APC could completely be excluded by light scatter gating. However, at 4-6 d after restimulation, as in the case of $\mathrm{NaB}$ treatments, cultures contained 5-10\% intact APC with the normal donor phenotype. Thus, the percentage of antigen-positive cells determined in untreated control cultures $(=\mathrm{APC})$ at the times indicated was always subtracted from the percentage assessed in treated cultures. $10^{4}$ cells were accumulated on a logarithmic scale to obtain one histogram. For cell sorting, all solutions were filter sterilized $(0.2 \mu \mathrm{m})$. Stained cells were suspended in complete medium at $10^{6}$ cells $/ \mathrm{ml}$ and sorted on a Cytofluorograph (Ortho Diagnostic Systems Inc., Westwood, MA) at a flow rate of 1,000 particles $/ \mathrm{s} .0 .5 \times 10^{6}$ fluorescence-positive cells were aseptically collected into 1.5 -ml Eppendorf tubes containing FCS. Sorted cells were harvested by centrifugation and subsequently restimulated.

Preparation of cell lysates and protein determination. $2 \mathrm{wk}$ after 5-azaC treatment cells were washed extensively. Cell lysates were prepared in extraction buffer containing $0.5 \%$ (wt/vol) NP-40 as described previously (4). Protein concentrations of cell lysates were determined with the bicinchoninic acid protein assay reagent (Pierce Chemical Co., Rockford, IL) and BSA as a standard according to the manufacturer's instruction. Protein concentrations were adjusted to 1 
$\mathrm{mg} / \mathrm{ml}$. To all assays $50 \mu \mathrm{l}$ of $\mathrm{T}$ cell lysate was added as a source for $\beta 3 \mathrm{Gal}-\mathrm{T}$ activity. Extracts were also prepared from control cultures consisting of APC alone.

Specific assay for $\beta 3$ Gal-T enzyme activity. $\beta 3 \mathrm{Gal}-\mathrm{T}$ activity in $\mathrm{T}$ cell lysates was assessed using asialo-ovine submaxillary mucin (OSM) as exogenous acceptor substrate as described by Berger et al. (27). Controls included reactions in the absence of exogenous acceptor substrate and full reaction mixtures stopped immediately (zero time). No difference was observed between these two controls. Control values were subtracted from values obtained after 30 and $60 \mathrm{~min}$ of incubation in the presence of added acceptor. Background activity contained in remaining APC was also determined and subtracted in each case. All measurements were carried out in duplicates.

The reaction mixture contained in a final volume of $100 \mu \mathrm{l}, 50 \mu \mathrm{l}$ of T cell lysate ( $50 \mu \mathrm{g}$ protein), $200 \mu \mathrm{g}$ of asialo-OSM, $2 \mu \mathrm{mol}$ GlcNAc (28), and $25 \mathrm{nmol}$ UDP- $\left[{ }^{14} \mathrm{C}\right] \mathrm{Gal}(14.600 \mathrm{cpm} / \mathrm{nmol}$; Amersham Corp., Arlington Heights, IL) in $25 \mathrm{mM}$ Tris ( $\mathrm{pH} 7.5$ ), $50 \mathrm{mM} \mathrm{NaCl}$, and $20 \mathrm{mM} \mathrm{MnCl}_{2}$ with $0.5 \%$ (wt/ vol ) NP-40. Reaction mixtures were incubated at $37^{\circ} \mathrm{C} .\left[{ }^{14} \mathrm{C}\right] \mathrm{Gal}$ incorporated into the glycoprotein acceptor was precipitated by the addition of $0.9 \mathrm{ml}$ of ice-cold $5 \%$ (wt/vol) phosphotungstic acid in $2 \mathrm{M} \mathrm{HCl}$. The precipitate was filtered over glass fiber filters (GF/A; Whatman Inc., Clifton, $\mathrm{NJ}$ ) and washed with excess phosphotungstic acid and ethanol $\left(-20^{\circ} \mathrm{C}\right)$ to remove the unreacted UDP- $\left[{ }^{14} \mathrm{C}\right] \mathrm{Gal}$. Filters were dried under vacuum and radioactivity was determined in a liquid-scintillation counter using $4 \mathrm{ml}$ of Toluol-Butyl-PBD (Ciba Geigy, Summit, NJ) as scintillation fluid.

\section{Results}

Tn antigen-positive T cells from a PMFP patient lack $\beta 3 G$ al-T activity. $\mathrm{Tn}+\mathrm{T}$ cells deficient in $\beta 3 \mathrm{Gal}-\mathrm{T}$ activity were cloned from the PBL of patient R.R. as described previously (4). These cloned lines were continuously expanded for $>1 \mathrm{yr}$ without alterations of the Tn phenotype. A clone belonging to the $\mathrm{CD} 4+$ subset was used to test for reexpression of $O$-glycosidic antigens. For this purpose, treated cells were probed by two mAbs as follows: in a first series we used $\mathrm{HH} 8$, which is directed to the TF antigen (Gal $\beta 1-3$ GalNAc-R) (Fig. 1), the product of $\beta 3 \mathrm{Gal}-\mathrm{T}$ activity. Since the TF antigen is sialylated after its

\begin{tabular}{|c|c|c|c|c|c|}
\hline & Structure & Designation & TKH6 & HH8 & DF-T1 \\
\hline $\mathrm{I}$ & $\square-\mathbf{R}$ & Tn & + & - & - \\
\hline 11 & $D \square-R$ & Sialosyl-Tn & - & - & $+(?)$ \\
\hline 111 & $\mathrm{O}-\square-\mathbf{R}$ & TF & - & + & - \\
\hline IV & $>$ & $\begin{array}{c}\text { Disialosyl-TF } \\
\text { (Tetrasaccharide) }\end{array}$ & - & - & + \\
\hline V & $+\mathrm{C}$ & Hexasaccharide & - & - & $+(?)$ \\
\hline
\end{tabular}

Figure 1. Schematic representation of O-linked carbohydrate epitopes and binding characteristics of anticarbohydrate $\mathrm{mAb}$. O-linked glycan structures expressed on normal or PMFP $\mathrm{T}$ cells are according to references 4 and 30 . The tetrasaccharide is typically expressed on resting $T$ cells whereas the hexasaccharide is characteristic for activated T cells (37). Although TKH6 and $\mathrm{HH} 8$ are carbohydrate-specific mAbs $(4,23)$, DF-T1 $(24)$ is a sialic acid-dependent mAb directed to CD43 (= leukosialin), a major O-glycan-bearing $\mathrm{T}$ cell surface protein (30). $R$, O-Ser/Thr-mucin.

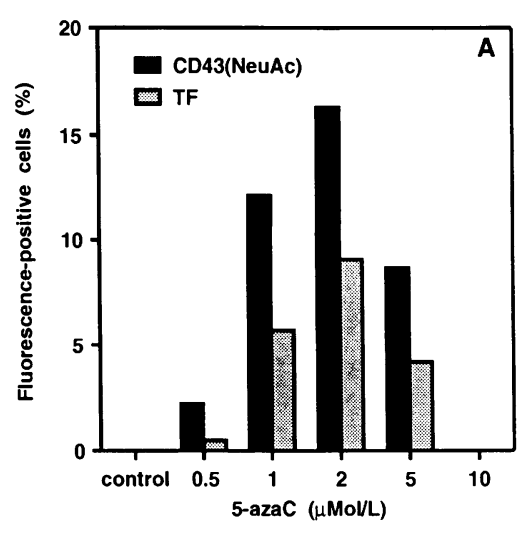

Figure 2. Reappearance of TF and CD43 $3_{\text {NeuAc }}$ antigens after treatment with 5-azaC. Drug-dose dependence $(A)$. PMFP $\mathrm{T}$ cells were cultured with $2 \mu \mathrm{M} 5$-azaC or in normal medium for 2 wk as described in Methods. Cells were labeled with $\mathrm{mAb}$ with (HH8) or without (DFT1) neuraminidase pretreatment. The respective percentage of positive cells was

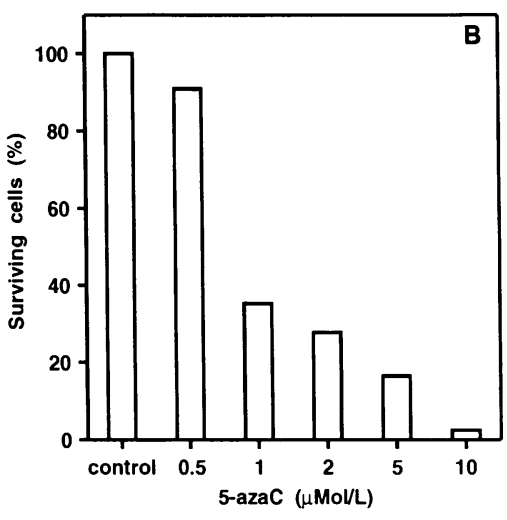

determined with a flow cytometer. Toxicity of 5-azaC $(B)$. An aliquot of the cells was used to determine the number of cells surviving drug treatment by trypan blue exclusion and was expressed as percentage of untreated control cells. Since $5-\mathrm{azaC}$ at 10 $\mu \mathrm{M}$ killed $>95 \%$ of the cells, analysis was not possible in those samples.

formation (29), enzymatic desialylation is a prerequisite for the binding of $\mathrm{HH} 8$ to the TF antigen. As previously reported, HH8 binds to normal but not to PMFP T cells (4). In a second series we used DF-T1 (24), which recognizes a sialylated epitope on CD43 (leukosialin or sialophorin), a major O-glycanbearing protein on $\mathrm{T}$ lymphocytes (30). CD43 on normal $\mathrm{T}$ cells carries on its extracellular domain 70-80 O-linked oligosaccharides consisting of the disialo-form of the TF antigen (NeuAc $\alpha 2-3 \mathrm{Gal} \beta 1$-3 [NeuAc $\alpha 2-6$ ] GalNAc-R) (Fig. 1 and reference 30$)$. The sialic acid-dependent mAb DF-T1 does not bind to PMFP T cells (see Fig. $3 O$ ), which are incompletely sialylated as a consequence of defective O-galactosylation (4). It was thus reasonable to assume that reactivation of $\beta 3 \mathrm{Gal}-\mathrm{T}$ activity should result in synthesis of the TF antigen and its subsequent sialylation in the reconstitution of the DF-T1 epitope. In addition to $\mathrm{HH} 8$ and DF-T1, we show data obtained with mAb TKH6 directed to the Tn antigen (GalNAc $\alpha$ 1-OSer/Thr) (Fig. 1). As previously shown, TKH6 binds to PMFP but not to normal $\mathrm{T}$ cells (4).

Induction of O-glycosidic antigens by 5-azaC. To test whether 5-azaC, an inhibitor of DNA methylation, could activate a silent nonmutant $\beta 3 \mathrm{Gal}-\mathrm{T}$ gene in PMFP $\mathrm{T}$ cells, a $\beta 3 \mathrm{Gal}-\mathrm{T}$-deficient $\mathrm{T}$ cell clone was treated a single time with varying concentrations of 5-azaC ranging from 0.5 to $10 \mu \mathrm{M}$. After 2 wk, the treated cells were labeled with HH8 and DF-T1 and analyzed by flow cytometry. A dose-dependent response that was obtained after 5-azaC treatment is presented in Fig. 2 $A$. Although untreated cells did not bind either of the two mAbs, after culture in 5-azaC-containing medium a sizeable portion of the survivors expressed the TF antigen and an always larger subset expressed the DF-T1 epitope. Peak induc- 




Figure 3. Flow cytograms of PMFP T cells grown with 5-azaC. PMFP T cells were cultured with $2 \mu \mathrm{M} 5$-azaC or in normal medium for 2 wk as described in Methods. For detection of TF antigen, cells were treated with $V$. cholerae neuraminidase before staining. Expression of the Tn (TKH6), TF (HH8) and CD43 $3_{\text {NeuAc }}(D F-T 1)$ antigens was analyzed. The phenotype of normal donor $\mathrm{T}$ cells is also presented. The ordinate (number of cells) is linear whereas the abscissa (cell fluorescence intensity) is a logarithmic scale.

tion was observed $\sim 2 \mu \mathrm{M}$. At higher concentrations $(5 \mu \mathrm{M})$ the induction frequency was impaired. The percentage of surviving cells at peak induction was $27 \%$ of untreated control cultures (Fig. $2 \mathrm{~B}$ ) in accordance with the observation that efficient induction is associated with a considerable decrease of the number of cells surviving 5-azaC treatment (13). No time course of exposure to 5-azaC was performed, since this compound was reported to be unstable in aqueous solution (26).

Representative flow cytograms demonstrating the effect of 5-azaC on PMFP T cells are presented in Fig. 3. The Tn antigen is expressed on PMFP (Fig. 3, $C$ and $D$ ) but not on normal donor T cells (Fig. 3, $A$ and $B$ ). Indeed, after exposure to 5azaC, a subpopulation of the treated PMFP cells failed to bind TKH6 (Fig. $3 E$ ). We believe that these cells are not actually $\mathrm{Tn}-$ in the sense of lacking GalNAc residues. It seems more likely that they express a modified Tn antigen such as the TF antigen or the sialosyl-Tn antigen (Fig. 1), since pretreatment with neuraminidase partly unmasked $\mathrm{Tn}$ antigen detectable by TKH6 (Fig. $3 F$ ). The TF antigen can be detected on normal desialylated T cells (Fig. $3 H$ ). In contrast, PMFP cells completely lack TF antigen (Fig. $3 J$ ) as previously described (4). Indeed, treatment of PMFP $\mathrm{T}$ cells with 5-azaC induced expression of TF antigen on a sizeable subset (Fig. $3 L$ ), suggesting reactivation of $\beta 3 \mathrm{Gal}-\mathrm{T}$. Moreover, as inferred from fluorescence intensity, TF antigen synthesis induced by 5-azaC appeared to reach a level comparable to normal donor $\mathrm{T}$ cells (Fig. 3, compare $L$ with $H$ ). However, pretreatment with neuraminidase was necessary to detect TF antigen (Fig. 3, compare $K$ with $L$ ), indicating subsequent and complete sialylation of the newly synthesized TF antigen. DF-T1 strongly labels normal donor T cells (Fig. $3 M$ ). Binding of DF-T1 is completely abolished by enzymatic desialylation (Fig. $3 N$ ). The sialic acid (NeuAc)-containing epitope is not expressed on PMFP T cells (Fig. $3 O$ ), which lack O-linked sialic acid because of defective O-galactosylation (4). Again, after 5-azaC treatment the DFT1 epitope was expressed on a large subset of the treated PMFP cells (Fig. $3 Q$ ). As in the case of control cells (Fig. $3 N$ ), the DF-T1 epitope expressed de novo on PMFP T cells proved to be sensitive to neuraminidase treatment (Fig. $3 R$ ).

Induction of $O$-glycosidic antigens by $N a B$. To answer the question whether reexpression of $\mathrm{TF}$ antigen and the CD43 $3_{\text {NeuAc }}$ epitope is specifically due to the mechanism of action of 5-azaC, similar experiments were carried out with $\mathrm{NaB}$.
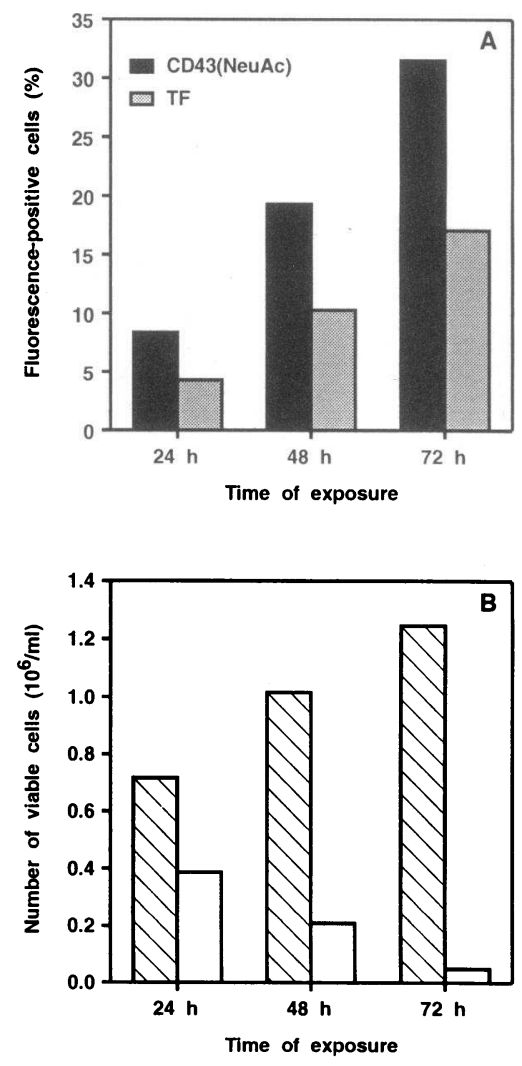

Figure 4. Kinetics of reexpression of TF and CD43 ${ }_{\text {NeuAc }}$ antigens induced by $\mathrm{NaB}(A)$. PMFP T cells were cultured with $2 \mathrm{mM} \mathrm{NaB}$ or in normal medium (as described in Methods) and harvested after the indicated times and prepared for flow cytometry. Effect of $\mathrm{NaB}$ on cell survival $(B)$. At the times indicated, the number of viable cells was determined in untreated (hatched bars) and in treated cultures (open bars) by trypan blue exclusion. 
Table I. Quantitative Assessment of 5-azaC and NaB Effects on Expression of Tn, TF, and CD43 ${ }_{\text {NeuAc Antigens }}$

\begin{tabular}{|c|c|c|c|c|c|c|c|c|}
\hline \multirow[b]{2}{*}{ Cells } & \multirow[b]{2}{*}{ Treatment } & \multirow[b]{2}{*}{$\mathrm{VCN}$} & \multicolumn{2}{|c|}{ Tn } & \multicolumn{2}{|c|}{ TF } & \multicolumn{2}{|c|}{$\mathrm{CD} 43_{\text {NeuAc }}$} \\
\hline & & & $\%$ & MFI & $\%$ & MFI & $\%$ & MFI \\
\hline \multirow[t]{2}{*}{ Normal donor $\mathrm{T}$ cells } & & - & 0.1 & 0.114 & 0.1 & 0.114 & 100.0 & 20.850 \\
\hline & & + & 0.2 & 0.115 & 93.9 & 5.701 & 0.2 & 0.151 \\
\hline \multirow[t]{6}{*}{ PMFP T cells } & & - & 97.9 & 23.020 & 0.4 & 0.151 & 0.7 & 0.154 \\
\hline & & + & 97.0 & 21.000 & 0.3 & 0.151 & 0.4 & 0.151 \\
\hline & $5-\operatorname{azaC}(2 \mu \mathrm{M})$ & - & 78.2 & 6.825 & 0.5 & 0.154 & 36.3 & 0.856 \\
\hline & $5-\operatorname{azaC}(2 \mu \mathrm{M})$ & + & 80.1 & 7.425 & 25.9 & 0.395 & 0.3 & 0.160 \\
\hline & $\mathrm{NaB}(2 \mathrm{mM})$ & - & 79.3 & 8.120 & 1.7 & 0.250 & 33.3 & 1.020 \\
\hline & $\mathrm{NaB}(2 \mathrm{mM})$ & + & 75.6 & 6.130 & 10.3 & 0.390 & 0.6 & 0.210 \\
\hline
\end{tabular}

The respective percentages (\%) of antigen-positive cells and the MFIs, indicating the quantity of antigens expressed per cell. The flow cytometric

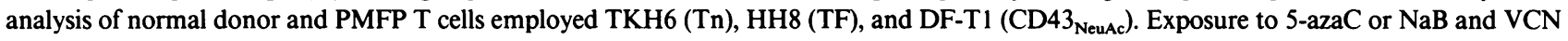
treatment before staining of the cells was carried out as described in Methods. VCN, V. cholerae neuraminidase.

This compound causes, among other effects, histone hyperacetylation $(19,20)$. In a preliminary test, PMFP $\mathrm{T}$ cells were exposed to $\mathrm{NaB}$ for $48 \mathrm{~h}$ at concentrations of 1 to $5 \mathrm{mM}(21)$. Indeed, expression of TF antigen and the DF-T1 epitope occurred gradually in a concentration-dependent manner from 1 to $3 \mathrm{mM}$. Higher concentrations of butyrate $(>4 \mathrm{mM})$ were very toxic and did not allow analysis. We have thus chosen a concentration of $2 \mathrm{mM}$ to determine the kinetics of induction of O-glycosylation by $\mathrm{NaB}$. As demonstrated in Fig. $4 \mathrm{~A}$, the induction was evident as a linear increase of the proportion of antigen-positive cells as a function of the time of exposure to
$\mathrm{NaB}$. Moreover, an increase of the mean channel of fluorescence intensity (MFI) indicated an increased quantity of antigens expressed per cell (not shown). The incubation time was limited to $72 \mathrm{~h}$, since $\mathrm{NaB}$ was very toxic on prolonged exposure (Fig. $4 \mathrm{~B}$ ). Table I summarizes the respective percentages and MFIs of representative induction experiments using 5azaC and $\mathrm{NaB}$. Flow cytometry results obtained after $\mathrm{NaB}$ treatment were qualitatively similar to those depicted in Fig. 3. A rather nonspecific inducing agent is DMSO, which causes differentiation of HL-60 and murine erythroleukemia cells $(18,20)$. In contrast to 5 -azaC and $\mathrm{NaB}$, treatment with $1.5 \%$
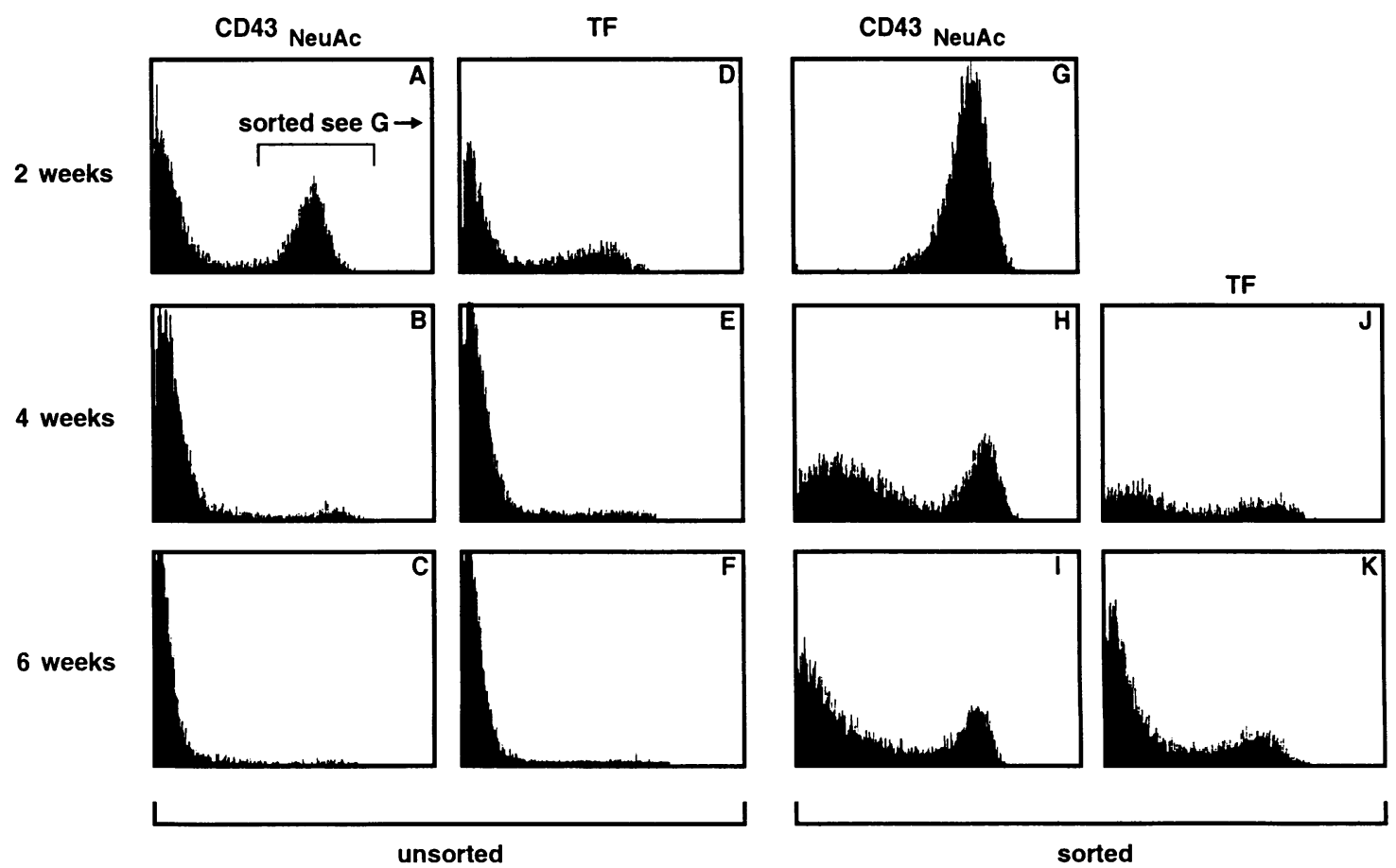

Figure 5. Stability of the 5-azaC-induced phenotype. PMFP T cells were cultured for 2 wk in the presence of $2 \mu \mathrm{M}$ 5-azaC. 5-azaC-responding cells $(A$ and $D)$ were isolated by FACS using DF-T1, reanalyzed subsequent to sorting $(G)$ or periodically restimulated (2-wk intervals) and reanalyzed with DF-T1 $(H$ and $I)$ or HH8 $(J$ and $K)$. In addition, the respective percentages were also determined in the mixed population that had not been subjected to cell sorting $(B, C, E$, and $F)$. 
DMSO (22) for 24, 48, and $72 \mathrm{~h}$ did not induce detectable O-glycosylation, suggesting that reexpression of O-glycosidic antigens is caused by 5 -azaC and $\mathrm{NaB}$ in a specific manner.

Stability of the 5-azaC-induced phenotype. To test the stability of the phenotype induced by 5-azaC, PMFP T cells were treated with 5 -azaC, maintained in culture, and periodically analyzed in 2-wk intervals. As depicted in Fig. 5, $A-F$, antigenpositive cells were clearly detectable at 4 (Fig. 5, $B$ and $E$ ) and 6 wk (Fig. 5, $C$ and $F$ ) after treatment. However, we observed that the percentage of antigen-positive cells decreased. To answer the question whether this was due to reversion to the original phenotype or to a growth disadvantage of the 5-azaC responding cells, treated cells were labeled with DF-T 12 wk after treatment and fluorescence-positive cells were isolated using a FACS (Fig. $5 G$ ) followed by periodic restimulations. Analysis at 2 (Fig. $5 H$ ) and 4 wk (Fig. $5 I$ ) after sorting ( 4 and 6 wk after 5-azaC treatment, respectively) revealed again that the cell population that bound DF-T1 decreased. Moreover, the staining patterns (Fig. 5, $H$ and $I$ ) suggested that, indeed, reversion back to the Tn phenotype contributes to the observed phenomenon. This observation suggests that the $\beta 3 \mathrm{Gal}-\mathrm{T}$ allele is only transiently derepressed in the treated cells. In addition, those cells that were enriched using DF-T1 also bound HH8 (Fig. 5, J and $K$ ), demonstrating that de novo biosynthesis of the TF antigen and its sialylation reconstitute the DF-T1 epitope.

Reappearance of $\beta 3 G$ al-T activity upon 5-azaC treatment. To unequivocally relate de novo expressed O-glycosidic anti-



Figure 6. Reactivation of $\beta 3 \mathrm{Gal}-\mathrm{T}$ activity in PMFP T cells. $\beta 3 \mathrm{Gal}-\mathrm{T}$ activity was determined in T cell lysates using asialo-OSM as acceptor substrate as described in Methods. All measurements were performed in duplicate and the experiment was carried out two times. Mean values of duplicates of one experiment are presented. Background activity determined in control cultures containing APC only was subtracted in each case. Activity was determined in untreated PMFP T cells $(\bullet)$ or in PMFP T cells exposed to $2 \mu \mathrm{M} 5$-azaC $(\Delta)$. Activity was also measured in normal donor $\mathrm{T}$ cells $(\bullet), \beta 3 \mathrm{Gal}-\mathrm{T}$ activity in individual cells responding to 5 -azaC was calculated from the activity measured in total lysates of treated PMFP cells on the basis of the percentage of TF antigen-expressing cells (25\%) in the same experiment as determined by flow cytometry $(\bullet)$. gens detected on the cell surface to the induction of $\beta 3 \mathrm{Gal}-\mathrm{T}$ activity, cellular enzyme activity was determined. Detergent cell lysates from 5-azaC-treated PMFP T cells and untreated control cells were assayed using asialo-OSM as acceptor substrate $(2,4,27)$. As depicted in Fig. 6 , no activity could be detected in untreated PMFP $T$ cells which is in accordance with the lack of detectable TF epitopes (Fig. $3 \mathrm{~J}$ ). On the other hand, pretreatment of PMFP cells with 5-azaC resulted in a significant increase of $\beta 3 \mathrm{Gal}-\mathrm{T}$ activity in the total lysate of the treated cells $\left(\sim 30 \mathrm{pmol} \cdot \mathrm{mg}^{-1} \cdot \mathrm{min}^{-1}\right)$. As shown by flow cytometry, activation of $\beta 3 \mathrm{Gal}-\mathrm{T}$ resulted in efficient TF antigen synthesis in $25 \%$ of the cells, indicating that in individual cells responding to 5 -azaC $\beta 3 \mathrm{Gal}-\mathrm{T}$ activity was indeed comparable to the activity present in normal donor $T$ cells ( 160 $\left.\mathrm{pmol} \cdot \mathrm{mg}^{-1} \cdot \mathrm{min}^{-1}\right)$. These data clearly demonstrated reactivation of $\beta 3 \mathrm{Gal}-\mathrm{T}$ in PMFP T cells.

Failure of 5-azaC and NaB to reactivate $\beta 3 \mathrm{Gal}-\mathrm{T}$ in Jurkat $T$ cells. The $\mathrm{T}$ lymphoblastoid leukemia cell line Jurkat also expresses the Tn antigen because of $\beta 3 \mathrm{Gal}-\mathrm{T}$ deficiency ( 31 ). It is unclear whether Jurkat $T$ cells represent transformed PMFP cells or originate from normal $\mathrm{T}$ cells that have lost gene activity during malignant transformation. Treatment of a Jurkat cell clone completely deficient in TF antigen synthesis (4) with 5 -azaC or $\mathrm{NaB}$ as described in Methods, however, did not induce de novo expression of $\mathrm{O}$-glycosidic antigens, suggesting that the gene encoding $\beta 3 \mathrm{Gal}-\mathrm{T}$ is either irreversibly repressed or mutated.

\section{Discussion}

More than a decade ago, deficiency of $\beta 3 \mathrm{Gal}-\mathrm{T}$ activity was shown to be the underlying enzymatic defect causing $\operatorname{PMFP}(2$, $3)$. A somatic mutation occurring at the stem cell level was suggested to be responsible for the loss of gene activity $(1,9)$ but thus far, the molecular nature of $\beta 3 \mathrm{Gal}-\mathrm{T}$ deficiency has not been analyzed due to a major experimental limitation: the enzyme deficiency was first reported to occur in erythrocytes (2) and thrombocytes (3). However, both represent only fragmented cells, which cannot be stimulated to undergo cell division. Gahmberg and colleagues ( 32 ) established a polyclonal B lymphoblastoid cell line with the Tn phenotype by EBV transformation but they did not report studies on the molecular mechanism causing $\beta 3 \mathrm{Gal}-\mathrm{T}$ deficiency. We have recently established $T$ cell clones with the intrinsic defect from the PBL of a well-characterized patient (4). These $T$ cell clones reflect an in vivo condition and thus provided the basis for investigations of the molecular nature of the PMFP defect.

In the present report, we have examined the possibility that deficient PMFP $T$ cell clones contain an intact but silent $\beta 3 \mathrm{Gal}-\mathrm{T}$ gene by treatment of deficient cells with agents known for their inducing effects on gene expression. Since gene suppression may occur at different levels we chose 5-azaC, an inhibitor of DNA methylation, and $\mathrm{NaB}$, an inhibitor of histone deacetylation. Both agents were successfully used to influence cell differentiation $(14,33,34)$ and to induce cellular genes (12,15-17) and viruses (35) in various cells, including human $\mathrm{T}$ lymphoid cells (21). Moreover, 5-azaC could reactivate silent glycosyltransferases in Chinese hamster ovary ( $\mathrm{CHO}$ ) cells (36), suggesting that DNA methylation also correlates with glycosyltransferase gene regulation. 
Indeed, exposure of PMFP T cells to 5-azaC results in induction of $\beta 3 \mathrm{Gal}-\mathrm{T}$ activity (Fig. 6). Furthermore, reactivation of $\beta 3 \mathrm{Gal}-\mathrm{T}$ activity induced by 5 -azaC and $\mathrm{NaB}$, respectively, could also be monitored by the reappearance of the TF antigen on the cell surface using a TF antigen-specific mAb capable of labeling lymphocytes (4) and flow cytometry (Fig. 3 ). In addition to the TF antigen, a sialylated epitope on CD43, which characterizes normal $\mathrm{T}$ cells, was expressed de novo on PMFP T cells after treatment with 5-azaC or $\mathrm{NaB}$. The molecular nature of some of the investigated epitopes need further analysis. We observed that the percentage of cells binding DF$\mathrm{T} 1$ was always higher than the percentage of $\mathrm{HH} 8$ binding cells, suggesting that de novo synthesis of the sialosyl-Tn antigen (Fig. 1) may be sufficient for binding of DF-T1. This hypothesis is supported by the fact that flow cytometry revealed a population unreactive with TKH6 after 5-azaC treatment (Fig. 3 $E)$. However, the Tn antigen was unmasked on some of these cells after treatment with neuraminidase (Fig. $3 F$ ). This subpopulation thus expresses the sialosyl-Tn antigen and may also bind the sialic acid-dependent DF-T1. An additional explanation would be that $\beta 1-6 \mathrm{~N}$-acetylglucosaminyltransferase normally induced during $T$ cell activation ( 37 ) could be coinduced after exposure to 5-azaC. The tetrasaccharide (Fig. 1, structure $I V$ ) expressed on normal resting $\mathrm{T}$ cells would then be converted to the hexasaccharide NeuAc $\alpha 2-3 \mathrm{Gal} \beta 1-3$ (NeuAc $\alpha 2-$ 3 Gal $\beta 1-4 G l c N A c \beta 1-6)$ GalNAc-R (Fig. 1, structure $V$ ). This further substitution of the TF antigen would definitely prevent binding of HH8 (4) but not necessarily binding of DF-T1. Surprisingly, DF-T1 binds to Jurkat T cells (not shown) in spite of deficient TF antigen synthesis in these cells $(4,31)$. Possibly, Jurkat T cells synthesize sialosyl-Tn antigens, which is supported by the observation that neuraminidase treatment enhances binding of TKH6 (not shown), or GlcNAc-containing derivatives of the Tn antigen with terminal sialic acid (37), providing epitopes for DF-T1. Thus, the phenotypes of PMFP and Jurkat $\mathrm{T}$ cells concerning $\mathrm{O}$-glycosylation are similar but not identical.

Development of the Tn phenotype may be the result of the repression of both $\beta 3 \mathrm{Gal}-\mathrm{T}$ gene copies, an event that may be accompanied by DNA methylation. An alternative possibility is that just one of the two alleles becomes repressed, resulting in functional hemizygosity (38). Subsequently, mutagenesis of the active allele would then lead to enzyme deficiency, and 5 -azaC or $\mathrm{NaB}$ will reactivate the silent nonmutant allele (39). However, the $\beta 3 \mathrm{Gal}-\mathrm{T}$ protein has not been purified to homogeneity nor has its cDNA been cloned. Thus, the molecular genetic analysis necessary to determine the actual mechanism(s) inducing $\beta 3 \mathrm{Gal}-\mathrm{T}$ deficiency must await the availability of molecular probes.

We have also to keep in mind that not necessarily the $\beta 3 \mathrm{Gal}-\mathrm{T}$ gene itself needs to be inactivated. A cellular transcription factor essential for expression of $\beta 3 \mathrm{Gal}-\mathrm{T}$ might as well be the target of the inactivation event leading to $\beta 3 \mathrm{Gal}-\mathrm{T}$ deficiency. The question, however, remains what induces $\beta 3 \mathrm{Gal}-\mathrm{T}$ gene repression. A possibility to be further investigated could be viral inactivation as suggested by the finding that viruses integrated in the host cell genome are suppressed by mechanisms including DNA methylation (39) and latent viruses can be induced by 5 -azaC (35) and $\mathrm{NaB}(21)$. Moreover, in Mov substrains of mice, insertion of a retrovirus induced de novo methylation of host DNA sequences and this change of the DNA methylation pattern correlated with the inactivity of a collagen gene (40).

$\beta 3 \mathrm{Gal}-\mathrm{T}$ deficiency is also observed in transformed $\mathrm{T}$ cells (Jurkat) (31) and in the majority of carcinomas that thereby accumulate the Tn antigen or synthesize the sialosyl-Tn antigen (8). It will be interesting to test whether carcinoma cells recover enzyme activity after treatment with agents such as 5 -azaC, $\mathrm{NaB}$, or other agents that interfere with gene expression. However, in our study 5-azaC and $\mathrm{NaB}$ failed to induce $\beta 3 \mathrm{Gal}-\mathrm{T}$ enzyme activity in Jurkat $\mathrm{T}$ cells, suggesting that the mechanism of inactivation is different in these cells. Nevertheless, the possibility that Jurkat cells contain an intact $\beta 3 \mathrm{Gal}-\mathrm{T}$ gene that is not inducible due to a more tight repression cannot be excluded. In addition, loss of gene expression in cancer cells of hematopoietic origin could also be due to gene translocations occurring during oncogenic transformation (41). Taken together, the $\beta 3 \mathrm{Gal}-\mathrm{T}$ locus appears to be very susceptible to gene inactivation events.

In summary, we present evidence that $\mathrm{T} n+\mathrm{T}$ cells from PMFP patient R.R. contain at least one intact $\beta 3 \mathrm{Gal}-\mathrm{T}$ allele, which is, however, persistently and strongly suppressed by a mechanism involving DNA methylation and histone deacetylation. We thus suggest that in stem cells or early hematopoietic progenitor cells of PMFP patients the $\beta 3 \mathrm{Gal}-\mathrm{T}$ site becomes inhibited during a "critical event," resulting in clonal inheritance of the repression into the various lineages.

\section{Acknowledgments}

We thank our patient R.R. for cooperation; Professor Dr. Henrik Clausen for generous supply of HH8 and TKH6 hybridoma supernatants; Dr. Marc Condrau, Dr. Christoph Fuchs, and Eva Niederer for help in flow cytometry; B. Berger for technical assistance; C. Gasser for excellent help in preparing the art work; Professor Dr. W. Schaffner, Dr. A. Lanzavecchia, and Dr. J. Biber for helpful suggestions; Dr. A. de la Hera for Jurkat cells; and Hoffmann-La Roche for recombinant human IL-2.

This work was supported by grant no. 31-30757.91 of the Swiss National Science Foundation to E. G. Berger.

\section{References}

1. Dahr, W., G. Uhlenbruck, H. H. Gunson, and M. van der Hart. 1975. Molecular basis of Tn-polyagglutinability. Vox Sang. 29:36-50.

2. Berger, E. G., and I. Kozdrowski. 1978. Permanent mixed-field polyagglutinable erythrocytes lack galactosyltransferase activity. FEBS (Fed. Eur. Biochem. Soc.) Lett. 93:105-108.

3. Cartron, J. P., and A. T. Nurden. 1979. Galactosyltransferase and membrane glycoprotein abnormality in human platelets from Tn-syndrome donors. Nature (Lond.). 282:621-623.

4. Thurnher, M., H. Clausen, W. Fierz, A. Lanzavecchia, and E. G. Berger. 1992. T cell clones with normal or defective O-galactosylation from a patient with permanent mixed-field polyagglutinability. Eur. J. Immunol. 22:1835-1842.

5. Salmon, C., J.-P. Cartron, and P. Rouger. 1984. The Human Blood Groups. Masson Publishing USA, Inc. 460 pp.

6. Bird, G. W. G., N. K. Shinton, and J. Wingham. 1971. Persistent mixedfield polyagglutination. Br. J. Haematol. 21:443-453.

7. Wallner, M., and R. Waldner. 1985 . Tn polyagglutinability occurring in a patient with B cell lymphoma. Blut. 51:355-360.

8. Springer, G. F. 1984. T and Tn, general carcinoma autoantigens. Science (Wash. DC). 224:1198-1206.

9. Vainchenker, W., G. Vinci, U. Testa, A. Henri, A. Tabilio, M.-P. Fache, H Rochant, and J. P. Cartron. 1985. Presence of the Tn antigen on hematopoietic progenitors from patients with the Tn syndrome. J. Clin. Invest. 75:541-546.

10. Yamamoto, F., H. Clausen, T. White, J. Marken, and S. Hakomori. 1990 Molecular genetic basis of the histo-blood group ABO system. Nature (Lond.). 345:229-233.

11. Bird, A. 1992. The essentials of DNA methylation. Cell. 70:5-8. 
12. Harris, M. 1982. Induction of thymidine kinase in enzyme-deficient Chinese Hamster Ovary (CHO) cells. Cell. 29:483-492.

13. Jones, P. A. 1984. Gene activation by 5-azacytidine. In DNA Methylation. Biochemistry and Biological Significance. A. Razin, H. Cedar, and A. D. Riggs, editors. Springer-Verlag, New York. 165-187.

14. Lee, K. H., T. Kinashi, K. Tohyama, K. Tashiro, N. Funato, K. Hama and T. Honjo. 1991. Different stromal cell lines support lineage-selective differentiation of the multipotential bone marrow stem cell clone LyD9. J. Exp. Med. 173:1257-1266.

15. Richardson, B., L. Kahn, E. J. Lovett, and J. Hudson. 1986. Effect of an inhibitor of DNA methylation on T cells. I. 5-azacytidine induces T4 expression on T8+ cells. J. Immunol. 137:35-39.

16. Gasson, J. C., T. Rydon, and S. Bourgeois. 1983. Role of de novo methylation in the glucocorticoid resistance of a T-lymphoid cell line. Nature (Lond.). 302:621-632.

17. Ballas, Z. K. 1984. The use of 5-azacytidine to establish constitutive IL-2 producing clones of EL4 thymoma. J. Immunol. 133:7-9.

18. Fischkoff, S. A., and R. M. Rossi. 1990. Lineage directed HL-60 cell sublines as a model system for the study of early events in lineage determination of myeloid cells. Leuk. Res. 14:979-988.

19. Kruh, J. 1982. Effects of sodium butyrate, a new pharmacological agent, on cells in culture. Mol. Cell. Biochem. 42:65-82.

20. Glauber, J. G., N. J. Wandersee, J. A. Little, and G. D. Ginder. 1991. 5 '-flanking sequences mediate butyrate stimulation of embryonic globin gene expression in adult erythroid cells. Mol. Cell. Biol. 11:4690-4697.

21. Golub, E. I., G. Li, and D. J. Volsky. 1991. Induction of dormant HIV-1 by sodium butyrate: involvement of the TATA box in the activation of the HIV-1 promoter. AIDS (Phila.). 5:663-668.

22. Sawai, M., K. Takase, H. Teraoka, and K. Tsukada. 1990. Reversible G1 arrest in the cell cycle of human lymphoid cell lines by dimethyl sulfoxide. Exp. Cell Res. 187:4-10.

23. Clausen, H., M. Stroud, J. Parker, G. F. Springer, and S. Hakomori. 1988. Monoclonal antibodies directed to the blood group A associated structure, galactosyl-A: specificity and relation to the Thomsen-Friedenreich antigen. $\mathrm{Mol}$. Immunol. 25:199-204.

24. Borche, L., F. Lozano, R. Vilella, and J. Vives. 1987. CD43 monoclonal antibodies recognize the large sialoglycoprotein of human leukocytes. Eur. J. Immunol. 17:1523-1526.

25. Böyum, A. 1968. Isolation of mononuclear cells and granulocytes from human blood. Scand. J. Clin. Lab. Invest. Suppl. 21(97, Pt. IV):77-89.

26. Notari, R. E., and J. L. DeYoung. 1975. Kinetics and mechanism of degradation of the antileukemic agent 5 -azacytidine in aqueous solution. $J$. Pharm. Sci. 64:1148-1157.
27. Berger, E. G., I. Kozdrowski, M. M. Weiser, D. H. van den Eijnden, and W. E. C. M. Schiphorst. 1978. Human serum galactosyltransferase: distinction, separation and product identification of two galactosyltransferase activities. Eur. J. Biochem. 90:213-222.

28. Van den Eijnden, D. H. W. E. C. M. Schiphorst, and E. G. Berger. 1983. Specific detection of $\mathrm{N}$-acetylglucosamine-containing oligosaccharide chains on ovine submaxillary asialo-mucin. Biochim. Biophys. Acta. 755:32-39.

29. Schachter, H., and I. Brockhausen. 1989. The biosynthesis of branched O-glycans. Symp. Soc. Exp. Biol. 43:1-26.

30. Fukuda, M. 1991. Leukosialin, a major O-glycan-containing sialoglycoprotein defining leukocyte differentiation and malignancy. Glycobiology. 1:347356.

31. Piller, V., F. Piller, and M. Fukuda. 1990. Biosynthesis of truncated O-glycans in the T cell line Jurkat. Localization of O-glycan initiation. J. Biol. Chem. 265:9264-9271.

32. Gahmberg, C., L. Peltokorpi, and L. C. Andersson. 1986. B lymphoblastoid cell lines with normal and defective O-glycosylation established from an individual with blood group Tn. Blood. 67:973-979.

33. Taylor, S. M., and P. A. Jones. 1979. Multiple new phenotypes induced in 10T1 / 2 and 3T3 cells treated with 5-azacytidine. Cell. 17:771-779.

34. Boyd, A. W., and J. W. Schrader. 1982. Derivation of macrophage-like lines from the pre-B lymphoma ABLS 8.1 using 5-azacytidine. Nature (Lond.) 297:691-694.

35. Ben-Sasson, S. A., and G. Klein. 1981. Activation of the Epstein-Barr virus genome by 5-azacytidine in latently infected human lymphoid lines. Int. J. Cancer 28:131-135.

36. Potvin, B., and P. Stanley. 1991. Activation of two new $\alpha(1,3)$ fucosyltransferase activities in Chinese hamster ovary cells by 5-azacytidine. Cell Regul. 2:989-1000.

37. Piller, F., V. Piller, R. I. Fox, and M. Fukuda. 1988. Human T-lymphocyte activation is associated with changes in O-glycan biosynthesis. J. Biol. Chem. 263:15146-15150.

38. Siminovitch, L. 1976. On the nature of heriditable variation in cultured somatic cells. Cell. 7:1-11.

39. Holliday, R. 1987. The inheritance of epigenetic defects. Science (Wash DC). 238:163-170.

40. Jähner, D., and R. Jaenisch. 1985. Retrovirus-induced de novo methylation of flanking host sequences correlates with gene inactivity. Nature (Lond.). 315:594-597.

41. Visvader, J., C. G. Begley, and J. M. Adams. 1991. Differential expression of the LYL, SCL and E2A helix-loop-helix genes within the hemopoietic system. Oncogene. 6:187-194. 